\title{
The Acquisition of Derivational Suffixes by Students of English at the University of Human Development
}

\author{
Inaad Mutlib Sayer and Sahima Abdulsalam \\ College of Languages, University of Human Development, Kurdistan Region - F.R Iraq
}

\begin{abstract}
Derivational suffixes are essential part of the competence of any foreign language learner, especially learners of English as a foreign language since English is a derivational language. They help the learners enrich their lexical repertoire, which is necessary in both speaking and writing. The present study tested the production and comprehension of derivational suffixes by third-year and fourth-year students of English as a foreign language at the University of Human Development. The aim was to examine the students' performance on the production and comprehension levels. Two tests were conducted on 112 students and seven one-way ANOVAs were performed to test the seven hypotheses of the study. The participants in the study were divided into two groups depending on their gender (79 females and 33 males) and into four groups depending on their proficiency level (pass, medium, good and very good). The results of the seven ANOVAs revealed that there were no significant gender differences among the students neither in the production test nor in the comprehension test. However, there were significant differences among the students according to the proficiency level in both tests. According to the frequency of the derivational suffixes, there were significant difference in the students' performance only in the comprehension test; in the production test, the difference was insignificant. Finally, the performance of the students in the comprehension test was much better than their performance in the production test.
\end{abstract}

Keywords: Derivational morphology, Derivational suffixes, Second language acquisition.

\section{Introduction:}

Learning a foreign language requires acquiring knowledge about its phonological, morphological, syntactic and semantic systems. Knowledge about the morphological system of a language gives the learner flexibility in using the vocabulary of the language. Part of the morphological knowledge of a foreign language is learning to recognize and produce the suffixes of that language. In English, suffixes are of two types: inflectional and derivational. There are only nine inflectional suffixes in English. These suffixes do not change the part of speech to which they are attached; they come last in a word; and only one suffix can be added to a word (Stageberg \& Oaks, 2000). By contrast, there are numerous derivational suffixes in English. These suffixes often, but not always, change the part of speech they are added to and more than one suffix may be attached to the same root (ibid.).

Derivational suffixes constitute a tangled area in foreign language learning for several reasons. Firstly, they are very large in number, which makes them almost impossible to memorize. Secondly, they are deceptive (Laufer, 1997) in the sense that their use does not have regularities. That is to say, they are attached to roots in an arbitrary way. For instance, all the verbs manage, fail, discover and invent can be changed into nouns by adding a derivational suffix to each. However, manage is made a noun by -ment, fail by -ure, discover by $-y$ and invent by -ion. Thirdly, knowledge of derivational suffixes is multifaceted (Nation, 2001). According to Tyler and Nagy (1989, p. 4) "full knowledge of derivational morphology involves at least three aspects, which" they "label lexical semantic, syntactic, and distributional knowledge". Lexical semantic knowledge is about the relatedness of words which share the same base. By means of this knowledge, the learner can recognize that the word analyze is related to analysis, but sent is unrelated to sentence. Syntactic knowledge assists the learner to assign syntactic categories to words. For instance, without knowing the meaning of the base necess-, the learner can identify necessary as an adjective and necessity as a noun. Distributional knowledge concerns the selectional restrictions on "the concatenation of stems and suffixes" (ibid). For example, the suffix ment attaches to verbs to form nouns but not to adjectives; thus, improvement is an acceptable word in English while quietment is not. Fourthly, the acquisition of derivational morphology is "an incremental process taking place over a period of time" (Schmitt \& Zimmerman, 2002, p. 149). Therefore, one expects the acquisition of English derivational morphology to be challenging to foreign learners.

The present study is concerned with the acquisition of derivational suffixes by Kurdish learners of English. The aim of the study is to examine the performance of these learners in comprehension and production tests in order to verify the following hypotheses:

1. There is no difference between genders in the comprehension of English derivational suffixes.

2. There is no difference between genders in the production of English derivational suffixes.

3. There is a significant difference between the participants' performances in the comprehension test according to their proficiency level.

Journal of University of Human Development

Volume 4 No. 4(2018); DOI: 10.21928/juhd. v4n4y2018.pp55-60

Regular research paper :(6) Received 28 July 2018; Accepted 31 August 2018; Published 13 October 2018

Corresponding author's e-mail: inaad.sayer@uhd.edu.iq, sahima.bdaiwi@uhd.edu.iq

Copyright $@ 2018$ Inaad Mutlib Sayer and Sahima Abdulsalam. This is an open access article distributed under the Creative Commons

Attribution License (CC BY-NC-ND 4.0) 
4. There is a significant difference between the participants' performances in the production test according to their proficiency level.

5. There is a significant difference between the participants' performances in the comprehension test according to the frequency of the derivational suffixes.

6. There is a significant difference between the participants' performances in the production test according to the frequency of the derivational suffixes.

7. The performance of the participants in the comprehension test is better than their performance in the production test.

\section{The importance of morphological knowledge:}

Morphological knowledge refers to the "conscious awareness of the morphemic structure of words and the ability to reflect on and manipulate that structure" (Carlisle, 1995, p. 194). Studies in vocabulary acquisition have provided evidence for the significance of morphological knowledge in learners' comprehension and production of vocabulary. Learners process morphologically complex words based on the level of morphological knowledge they have achieved. Carlisle (2003) believes that morphological knowledge begins developing at early stage of schooling and continue developing into adulthood.

Wysochi and Jenkins (1987) conducted a similar study on 217 fourth-, sixth- and eighth-grade students. The purpose of this study was to examine whether context, morphological knowledge, or both are used to infer the meaning of unfamiliar words. The researchers observed that strong contextual clues were helpful to all grade levels; however, they were more helpful to older graders. In situations where the contextual clues were weak, the sixth- and eighth-grade students outperformed the fourth-grade students by resorting to morphological knowledge to decipher unfamiliar words.

White, Power, and White, (1989) conducted two studies. In the first study, they examined a sample of 257 prefixed words to determine (a) their analyzability, (b) the frequency of analyzable words by grade, and (c) the number and type of suffixes, and the proportion of these that cause changes in pronunciation or spelling. They found that "about 80 percent of the major prefixed words were analyzable" (ibid, 292). As far as frequency is concerned, they found that "the number of analyzable target words in the American Heritage corpus for each grade increased sharply from Grade 3 to Grade 7" (ibid). Regarding the number and type of suffixes, the study revealed that "about 80 percent of the analyzable target words also had suffixes. About 90 percent of the terminal suffixes were inflectional suffixes or neutral derivational suffixes" (ibid). The second study of White et al. (1989) involved third and fourth grade students. The aim was to examine these students' morphological knowledge. The results showed that morphological knowledge improves with age and experience.

Carlisle and Nomanbhoy (1993) emphasized the role of morphological knowledge during the early stages of reading development, but the role becomes much more significant during the development of more advanced reading skills. A study by Anglin (1993) examined the relationship between morphological knowledge and vocabulary learning in children. The results of the study indicated that there was a dramatic improvement in the comprehension of complex words from $1^{\text {st }}$ to $5^{\text {th }}$ grade.

Carlisle (2000) investigated the significance of morphological knowledge in the reading comprehension of $3^{\text {rd }}$ and $5^{\text {th }}$ grade children. The results revealed that morphological knowledge has a significant role in the children's ability to recognize morphologically complex words and that $43 \%$ of the variance in reading comprehension at the $5^{\text {th }}$ grade level was due to the children's morphological knowledge.

Betram, Laine, and Virkkala (2000) studied "how morphological knowledge contributes to Finnish children's understanding of words" (p. 288). They measured the participants' performance against the frequency of the test words and the productivity of the suffixes in the test words. The results showed a main significant effect for both frequency and productivity. The participants performed much better on high-frequency words than they did on low-frequency words. In addition, the participants were better at understanding the meaning of words ending in high-productive suffixes than the words ending in low-productive suffixes. However, even with high frequency and high productivity, there was a need for morphological knowledge in the understanding of complex words.

Bellomo (2009) investigated the effect of morphological analysis on the acquisition of vocabulary among college preparatory students with heterogeneous language backgrounds. Bellomo concluded that "morphological analysis as a vocabulary acquisition and retention strategy can benefit college preparatory students irrespective of their language origin" (p. 20).

McCutchen and Logan (2011) examined the effect of morphological information on students' ability to comprehend and produce new words in a given context. "The morphological production task provided children with a word and required them to produce a derivation to fit a sentence context, thus tapping syntactic aspects of morphological knowledge" (p. 336). The researchers found that there is connection between the students' abilities to produce correct derivational forms and morphological awareness.

\section{Previous work on $\mathrm{L} 2$ acquisition of derivational morphology:}

Little work has been executed on the L2 acquisition of derivational morphology. Schmitt (1998) conducted a longitudinal study on three $\mathrm{PhD}$ students to examine their productive derivational knowledge. The study revealed that, though the students were exposed to an environment rich in derived words, two of them did not show significant advance in their knowledge of derivational morphology.

Dehham (2015) investigated the comprehension and production of adjectival suffixes by 150 fourth-year students of English at three Iraqi universities, namely Babylon, Baghdad, and Al-Qadissiya, during the academic year 2014 - 2015. The main aim of Dehham's study was to measure "the Iraqi EFL university learners' performance in recognizing and producing adjectival affixes" (p. 15). The statistical analysis of the data revealed that EFL Iraqi learners at university level face difficulties at the comprehension and production level alike (the percentage of correct responses was $48.19 \%$ in the comprehension test and $29.89 \%$ in the production test). The results 
also showed that the performance of EFL Iraqi learners in the comprehension test outweighed their performance in the production test.

Alotaibi and Alotaibi (2017) conducted a research on 90 Kuwaiti undergraduate students, 50 intermediate and 40 advanced. The purpose of this research was to measure the students' performance in comprehending and producing English derivational suffixes. A multiple-choice test was used to elicit data concerning the comprehension skill and a fill-in the blank test was applied to collect data about the production skill. The participants were tested in two types of derivational suffixes, neutral and non-neutral suffixes. The calculations indicated that there was a statistically significant difference between the intermediate group and the advanced group in both the comprehension and the production tests. However, the participants performed better in the comprehension test than they did in the production test.

\section{Methodology:}

\section{Participants:}

The participants in the study consist of 112 English language students at the University of Human Development - Kurdistan Region - Iraq. They are in the third and fourth stages of their B.A. programme in English language and literature. All the participants have studied derivational suffixes within the course of English Morphology. The ages of the participants range between 20 and 25 years. The participants were divided into two groups according to their sex (79 females and 33 males) and into four groups according to their proficiency level (50-59 = pass, 60-69 = medium, 70-79 = good, and $80-89=$ very good $)^{1}$. The consent of the participants was ensured before conducting the tests.

\section{Material:}

The material of the research consists of the participants' responses to two tests. The first was a multiple-choice test which was designed to measure the participants' performance in comprehending English derivational suffixes. The second was a fill-in-the-blanks test, which was intended to measure the participants' performance in producing English derivational suffixes.

1. This division of proficiency levels is based on the system used in Iraqi universities.

Twelve English derivational suffixes were selected according to their frequency in the British National Corpus (BNC) to be used in both tests. Four suffixes have high frequency, namely -ly adverbial $(111,045), \quad$-ion $(52,016)$, -ty $(38,421)$, -al adjectival $(37,583)$; four suffixes have medium frequency, namely -ous $(8,116)$, -or $(7,837)$, ic $(7,500)$, -al nominal $(7,384)$; and four suffixes have low frequency, namely -ways (35), -ie diminutive (18), -ette diminutive(14), -let diminutive (10). The frequencies of the suffixes were determined following Laws and Ryder (2014) MorphoQuantics: http://morphoquantics.co.uk.

Each test included twelve authentic sentences cited from online Oxford living Dictionaries: https://en.oxforddictionaries.com/

\section{Results:}

Seven one-way ANOVAs were performed to test the seven hypotheses of the current study. ANOVA1 tested the first hypothesis that there is no difference between genders in the comprehension of English derivational suffixes. The results of the analysis revealed that $F(1,110)=0.05, p=.81$ (Table 1$)$. Accordingly, the null hypothesis is accepted.

Table 1:

One-way ANOVA analysis of the comprehension

test responses according to the subjects' gender

\begin{tabular}{lcccccc}
\hline \multicolumn{1}{c}{ Gender } & $\mathrm{N}$ & $\mathrm{M}$ & $\mathrm{SD}$ & $F$ & $P$-value & $F$ crit \\
\hline Females & 79 & 7.35 & 1.82 & 0.05 & 0.81 & 3.92 \\
Males & 33 & 7.45 & 2.41 & & & \\
\hline \multicolumn{7}{l}{ Note: $p \leq 0.05$}
\end{tabular}

ANOVA2 was conducted to test the second hypothesis that there is no difference between genders in the production of English derivational suffixes. The results of the test were as follows: $F$ (1, $110)=0.84, p=.36$ (Table 2). Therefore, the null hypothesis is accepted.

\section{Table 2:}

One-way ANOVA analysis of the production test responses according to the subjects' gender

\begin{tabular}{lcccccc}
\hline \multicolumn{1}{c}{ Gender } & N & M & SD & $F$ & $P$-value & $F$ crit \\
\hline Females & 79 & 3.90 & 1.72 & 0.84 & 0.36 & 3.92 \\
Males & 33 & 4.24 & 1.98 & & & \\
\hline \multicolumn{7}{c}{ Note: $p \leq 0.05$}
\end{tabular}

ANOVA3 was intended to test the third hypothesis that there is a significant difference between the performances of the participants in the comprehension test according to their proficiency level. The test revealed that $F(3,108)=4.91, p=.003$ (Table 3). So, the alternative hypothesis is accepted.

Table 3:

One-way ANOVA analysis of the comprehension test responses according to the subjects' proficiency level

\begin{tabular}{lcccccc}
\hline \multicolumn{1}{c}{ Proficiency level } & N & M & SD & $F$ & $P$-value & $F$ crit \\
\hline Pass & 46 & 7.02 & 1.72 & 4.91 & 0.003 & 2.68 \\
Medium & 32 & 6.94 & 2.03 & & & \\
Good & 23 & 7.87 & 2.20 & & & \\
Very good & 11 & 9.18 & 1.54 & &
\end{tabular}

ANOVA4 tested the fourth hypothesis that there is a significant difference between the performances of the participants in the production test according to their proficiency level. The results of the test showed that $F(3,108)=5.61, p=.001$ (Table 4). Therefore, the alternative hypothesis is accepted.

Table 4:

One-way ANOVA analysis of the production test subjects' proficiency level 


\begin{tabular}{lcccccc}
\hline \multicolumn{1}{c}{ Proficiency level } & $\mathrm{N}$ & $\mathrm{M}$ & $\mathrm{SD}$ & $F$ & $P$-value & $F$ crit \\
\hline Pass & 46 & 3.35 & 1.54 & 5.61 & 0.001 & 2.68 \\
Medium & 32 & 4.03 & 1.82 & & & \\
Good & 23 & 4.61 & 1.59 & & & \\
Very good & 11 & 5.36 & 2.16 & & \\
\hline \multicolumn{7}{c}{ Note: $p \leq 0.05$}
\end{tabular}

ANOVA5 was performed to test the fifth hypothesis that there is a significant difference between the participants' performances in the comprehension test according to the frequency of the derivational suffixes. The analysis resulted in being $F(2,9)=9.60, p=.006$ (Table 5). Accordingly, the alternative hypothesis is accepted.

Table 5:

One-way ANOVA analysis of the comprehension test responses according to the frequency of suffixes

\begin{tabular}{lcccccc}
\hline \multicolumn{1}{c}{ Frequency of suffixes } & $\mathrm{N}$ & $\mathrm{M}$ & $\mathrm{SD}$ & $F$ & $P$-value & $F$ crit \\
\hline High frequency & 4 & 89.75 & 8.62 & 9.60 & 0.006 & 4.25 \\
Medium frequency & 4 & 82.5 & 21.21 & & & \\
Low frequency & 4 & 34.5 & 24.56 & & & \\
\hline \multicolumn{7}{c}{ Note: $p \leq 0.05$}
\end{tabular}

ANOVA6 tested the sixth hypothesis of the present study that there is a significant difference between the participants' performances in the production test according to the frequency of the derivational suffixes. The results of the test revealed that $F(2,9)=4.12, p=.054$ (Table 6). Therefore, the alternative hypothesis is rejected.

Table 6:

One-way ANOVA analysis of the production frequency of suffixes

\begin{tabular}{lcccccc}
\hline \multicolumn{1}{c}{ Frequency of suffixes } & $\mathrm{N}$ & $\mathrm{M}$ & $\mathrm{SD}$ & $F$ & $P$-value & $F$ crit \\
\hline High frequency & 4 & 63.75 & 36.81 & 4.12 & 0.054 & 4.25 \\
Medium frequency & 4 & 35.25 & 20.68 & & & \\
Low frequency & 4 & 13 & 10.10 & & & \\
\hline \multicolumn{6}{c}{ Note: $p \leq 0.05$}
\end{tabular}

ANOVA7 was conducted to test the seventh hypothesis of this research which states that the performance of the participants in the comprehension test is better than their performance in the production test. The analysis showed that $F(1,22)=6.14, p=.02$ (Table 7). Thus, the alternative hypothesis is accepted.

Table 7:

One-way ANOVA analysis of the responses to both production tests

\begin{tabular}{lcccccc}
\hline \multicolumn{1}{c}{ Type of test } & $\mathrm{N}$ & $M$ & $\mathrm{SD}$ & $F$ & $P$-value & $F$ crit \\
\hline Comprehension & 12 & 68.92 & 31.03 & 6.14 & 0.02 & 4.30 \\
Production & 12 & 37.33 & 31.38 & & & \\
\hline \multicolumn{7}{c}{ Note: $p \leq 0.05$}
\end{tabular}

The calculations in table 8 below indicate that scores of the participants in both the comprehension and production of highfrequency suffixes are higher than their scores in the comprehension and production of medium frequency and low frequency suffixes.

Table 8:

Frequencies and percentages of correct answers for all the suffixes used in both the comprehension test and the production test

\begin{tabular}{|c|c|c|c|c|c|c|c|}
\hline \multirow{2}{*}{ frequency } & \multirow{2}{*}{ suffixes } & \multicolumn{2}{|c|}{ comprehension } & \multicolumn{2}{|c|}{ production } & \multirow{2}{*}{$\begin{array}{c}\text { comprehension } \\
\text { mean }\end{array}$} & \multirow{2}{*}{$\begin{array}{c}\text { production } \\
\text { mean }\end{array}$} \\
\hline & & frequency & percentage & frequency & percentage & & \\
\hline \multirow{4}{*}{$\begin{array}{l}\text { high } \\
\text { frequency } \\
\text { suffixes }\end{array}$} & -ly adverbial & 80 & 71.43 & 74 & 66.07 & \multirow{4}{*}{80.13} & \multirow{4}{*}{56.92} \\
\hline & -ion & 89 & 79.46 & 12 & 10.71 & & \\
\hline & -ty & 101 & 90.18 & 70 & 62.5 & & \\
\hline & -al adjectival & 89 & 79.46 & 99 & 88.39 & & \\
\hline \multirow{4}{*}{$\begin{array}{l}\text { medium } \\
\text { frequency } \\
\text { suffixes }\end{array}$} & -ous & 103 & 91.96 & 8 & 7.14 & \multirow{4}{*}{73.66} & \multirow{4}{*}{31.47} \\
\hline & -Or & 80 & 71.43 & 40 & 35.71 & & \\
\hline & $-\mathrm{ic}$ & 93 & 83.04 & 58 & 51.79 & & \\
\hline & -al nominal & 54 & 48.21 & 35 & 31.25 & & \\
\hline \multirow{4}{*}{$\begin{array}{c}\text { low } \\
\text { frequency } \\
\text { suffixes }\end{array}$} & -ways & 23 & 20.54 & 7 & 6.25 & \multirow{4}{*}{30.80} & \multirow{4}{*}{11.61} \\
\hline & -je diminutive & 36 & 32.14 & 23 & 20.54 & & \\
\hline & -ette diminutive & 11 & 9.82 & 20 & 17.86 & & \\
\hline & -let diminutive & 68 & 60.71 & 2 & 1.79 & & \\
\hline \multicolumn{6}{|c|}{ overall mean } & 61.53 & 33.33 \\
\hline
\end{tabular}

\section{Discussion:}

The study has shown that gender has no effect on the comprehension and production of English derivational suffixes. This was expected and previous studies on the acquisition of derivational suffixes did not include gender as a variable. In our study, gender was included as a variable in order to demonstrate that it has no effect on the comprehension and production of English derivational suffixes statistically.

Our study, like previous studies, has revealed that there is ato the significant relationship between the proficiency level of the participants and the comprehension and production of English derivational suffixes. Therefore, hypotheses 3 and 4 are both accepted. This finding is consistent with White et al.'s (1989) conclusion that morphological knowledge improves based on the level of proficiency. Moreover, Freyd and Baron (1982) reported that the advanced group in their study outperformed the regular group in implementing morphological knowledge to analyze complex words. Similarly, in Alotaibi and Alotaibi (2017) study, the advanced learners performed better than the intermediate learners did in both the comprehension and the production tests.

Frequency of English derivational suffixes has a significant effect on the comprehension of these suffixes by students of English at University of Human Development (UHD) but it has no effect on their production of these suffixes. Accordingly, hypothesis 5 is accepted while hypothesis 6 is rejected. This result is in line with a finding by Bertram et al. (2000) that frequency has a significant effect on the comprehension of derived words.

Although the frequency of derivational suffixes and the derivatives formed from them in a native speakers' environment (BNC in the context of this study) is important, it is not a determinant factor in foreign language acquisition. The researchers believe that the frequency of the suffixes and the derivatives in the foreign language learners' environment is more important and has greater effect on the comprehension and production of the learners than their frequency in the native speakers' environment. Therefore, the EFL learners will be able to comprehend and produce aspects of the foreign language, including derivational suffixes and their derivatives, which they are frequently exposed to in their own environments much better than 
those aspects which have high frequency in the native speakers' environment but rarely used in the EFL learners' environment. And we mean by the EFL learners' environment every context in which the learners are exposed to the foreign language, including the classroom lectures, the textbooks, the media, the social media, the classmates chat, etc. This might explain why the suffixes -ous and $i c$, which have medium frequency in the BNC, obtained very high number of correct answers, even higher than most of suffixes in the high frequency list according to BNC ( Table 8).

Even within the learners' environment, the frequency of the derivative is more important than the frequency of the suffix itself. This will be clear if we consider the high variance in the correct answers received by the suffix -ion in the comprehension and production tests $(89,12$ respectively). This may be due, besides other factors that contribute to the difficulty of the production test, to the frequency of the derivatives revision and rebellion in the participants' environment. The researchers guess that revision might have higher frequency than rebellion in the participants' environment. This is also true of the derivatives dangerous and mountainous, and booklet and starlet, which obtained highly variant correct responses although they are formed by the same suffix respectively. Again, we think that this is so because dangerous and booklet might be more frequent than mountainous and starlet in the participants' environment.

Analysis of the data on the comprehension and the production of English derivational suffixes by UHD students has revealed that the students' performance in the comprehension test is much better than their performance in the production test. This result is echoed by Dehham (2015) and Alotaibi and Alotaibi (2017) who found that the subjects of their studies performed much better in the comprehension test than they did in the production test.

Schmitt and Zimmerman (2002) reported that the production of derivatives is more complex than the reception. Besides, Jiang (2000) proposed three stages of vocabulary acquisition and the learning of morphological specifications takes place at the third stage. However, "...a majority of L2 words fossilize at the second stage" (p. 47). Similarly, Jullian (2000) believes that advanced L2 learners often can communicate with restricted vocabulary, so that they do not bother themselves to learn new words. They experience what Jullian (2000, p. 37) calls a "lexical acquisition plateau". In the same vein, Laufer (1991) states that advanced L2 learners do not feel the need to increase their lexical repertoire as far as they can communicate with restricted vocabulary. Furthermore, she argues that "Even though our passive vocabularies develop throughout our lifetime, long after the grammar of a language has been acquired, our productive lexicon will grow only until it reaches the average level of the group in which we are required to function" (p. 445).

This result might also be ascribed to the fact that the context in the comprehension test is more helpful than the context in the production test. In each item of the comprehension test, the participant has four derivatives, each belonging to a different syntactic category. Syntactic knowledge about the category of each derivative and the category required to fill the blank in each item in the test will definitely help the participant choose the right answer. However, in the production test, such syntactic knowledge is not helpful. Here, the participant has to add an appropriate derivational suffix to a base to form a derivative which fills the blank. The fact that several derivational suffixes can be added to the same base in an arbitrary way makes the task of the participant in the production test more difficult.

\section{Conclusion:}

The calculations of the current study provide statistical evidence that there is a connection between the frequency of the derivational suffixes and L2 learners' comprehension of derived words. The study also provides statistical evidence that the proficiency of the learners plays a significant role in the acquisition of derivational morphology. However, acquiring the productive aspects of derivational morphology is a more complex process than acquiring the receptive aspects.

In addition, it can be said that Kurdish learners of English, like other foreign learners of English, face difficulties in the production of English derivational suffixes. This conclusion is supported by Dehham (2015) who found that Iraqi learners of English have trouble in recognizing and producing adjectival suffixes. Moreover, Schmitt and Zimmerman (2002) suggest that “....acquiring the productive use of derivative members of a word family can be problematic for learners of English" (p. 151). Therefore, we recommend teachers to allocate more time for this area of language learning and give the learners more chance to practice producing derivational suffixes and the derivatives formed by attaching them to different bases.

\section{References:}

Alotaibi M. A. \& Alotaibi, A. M. (2017). On the Acquisition of Derivational Suffixes by Kuwaiti EFL Learners. European Scientific Journal, 13(17), 223-238. doi: 10.19044/esj.2017.v13n17p223

Anglin, J. (1993). Vocabulary development: A morphological analysis. Monographs of the Society for Research in ChildDevelopment, 58(10, Serial No. 238).

Bellomo, T.S. (2009). Morphological Analysis as a Vocabulary Strategy for L1 and L2 College Preparatory Students. TESL-EJ, 13(3),1-27.

Bertram, R. Laine, M. \& Virkkala, M. M. (2000). The role of derivational morphology in vocabulary acquisition: Get by with little help from my morpheme friends. Scandinavian Journal of Psychology. 41(4), 287-296.

British National Corpus (2001). Available from the Oxford University Computing Services Web site, http://info.ox.ac.uk/bnc/.

Carlisle, J. F. (1995). Morphological awareness and early reading achievement. In L. B. Feldman (Ed), Morphological aspects of language processing, (pp. 157-188). Hillsdale, NJ: Lawrence Erlbaum Associates.

Carlisle, J. F. (2000). Awareness of the structure and meaning of morphologically complex words: Impact on reading. Reading and Writing, 12(3), 169-190. 
Carlisle, J. F. (2003). Morphology matters in learning to read: A commentary. Reading Psychology, 24(3), 291-322.

Carlisle, J. F. \& Nomanbhoy, D. (1993). Phonological and morphological awareness in first graders. Applied Psychlinguistics, 4, 177-195.

Dehham, S.H. (2015). The use of English adjectival affixes by Iraqi EFL learners: An error analysis. English Linguistics Research, 5(1),14-31.

Jiang, N. (2000). Lexical representation and development in a second language. Applied Linguistics, 21(1), 47-77. doi: 10.1093/applin/21.1.47.

Jullian, P. (2000). Creating word-meaning awareness. English Language Teaching Journal, 54, 37-46.

Laufer, B. (1991). The development of lexis in the production of advanced L2 learners. Modern Language Journal, 75, 440448.

Laufer, B. (1997). What's in a word that makes it hard or easy? Some intralexical factors that affect the learning of words. In N. Schmitt \& M. McCarthy (Eds.), Vocabulary: Description, acquisition and pedagogy (pp. 140-155). Cambridge: Cambridge University Press.

Laws, J. V. \& Ryder, C. (2014). MorphoQuantics: http://morphoquantics.co.uk

Laws, J. V. \& Ryder, C. (2014). Getting the measure of derivational morphology in adult speech: A corpus analysis using MorphoQuantics. Language Studies Working Papers: University of Reading, 6, 3-17.

McCutchen, D. \& Logan, B. (2011). Inside incidental word learning: Children's strategic use of morphological information to infer word meanings. Reading Research Quarterly, 46(4), 334-349.

Nation, I. S. P. (2001). Learning vocabulary in another language. Cambridge: Cambridge University Press.

Oxford living Dictionaries: https://en.oxforddictionaries.com/

Schmitt, N. (1998). Tracking the incremental acquisition of second language vocabulary: A longitudinal study. Language Learning, 48, 281-317.

Schmitt, N. \& Zimmerman, C. B. (2002). Derivative word forms: What do learners know? TESOL Quarterly, 36(2), 145-171.

Stageberg, N. C. \& Oaks, D. D. (2000). An Introductory English

Grammar. $5^{\text {th }}$ edition. Boston, Heinle.
Tyler, A. \& Nagy, W. (1989). The acquisition of English derivational morphology. Journal of Memory \& Language, 28, 649667.

White, T.G., Power M.A. \& White, S. (1989). Morphological analysis: Implications for teaching and understanding vocabulary growth. Reading Research Quarterly, 24(3), 283-304.

Wysocki, K. \& Jenkins, J. R. (1987). Deriving Word meanings through morphological generalization. Reading Research Quarterly, 22(1), 66-81. 